\title{
Low Voltage Ride through Capability Improvement of DFIG using Feed Forward Current Regulator.
}

\author{
Prof. D.S. Bankar, ${ }^{1}$ \\ Associate Professor, \& Ph.D candidate of Electrical \\ Engineering Department of Bharati Vidyapeeth University \\ College of Engineering \\ Pune-411043,India \\ dsbankar@bvucoep.edu.in , M: 9226899338
}

\author{
Prof. (Dr.) D.B. Talange ${ }^{2}$ \\ Ph.D IIT Bombay, currently working as Professor in \\ Electrical Engineering Department of Govt. College of \\ Engineering \\ Pune-411005,India \\ dbt.elec@coep.ac.in , M: 9325117504
}

\begin{abstract}
Day by day wind power technology is more dominating on the other types of renewable energy sources. Out of different types of generators doubly fed induction generator is more popular due to its superior controlling characteristics of active and reactive power at sub synchronous and super synchronous speed. But whenever there is any fault on the grid which causes voltage dip, the performance of the DFIG is affected since its stator and rotor are connected to the grid. When voltage sag occurs on the stator terminals, a transient current appears on the rotor converter which may damage the rotor side converter. The grid code suggests that these wind power plants should remain connected to the grid under such circumstances and contribute the fault current safely. But it is difficult to satisfy for DFIG connected wind plants. This paper presents the feed forward current regulator for rotor side converter of DFIG and analyses its low voltage ride through capability.
\end{abstract}

Keywords-DFIG, RSC, GSC, LVRT.

\section{INTRODUCTION}

Wind power technology is the most adopted power technology in the renewable energy systems and doubly fed induction generators are more popular in wind turbine technology. DFIG has several advantages on the other types of generator like superior control on the active and reactive power. Also the power electronics are connected in the rotor circuit only $30 \%$ of power is handled by the power electronics hence the harmonics generated by the system are quite low. Also these generators can generate the electricity below as well as above synchronous speed. But DFIG suffers from the drawback that under grid connected system whenever there is any fault which causes the voltage dip on the stator terminals, it causes the dc component in the stator current and causes increase in the dc flux linking with the rotor circuit. This causes the transient currents at rotor terminals which have to be handled by the rotor side converter. Therefore RSC has to be over modulated. To handle the situation common technique is to disconnect the RSC in the event of the grid faults and rotor terminals to be connected to the external resistance circuit which is well known as crowbar circuit. Under such circumstances the DFIG now act as normal induction motor rather than the generator and draws the reactive power from the supply. This happens exactly when the grid needs the reactive power support. A disconnection of large wind farm in such conditions may cause the collapse of the entire grid.

The use of crowbar circuit should be the last choice to limit transient rotor currents. This paper proposes a feedforward current control (FFCC) scheme for the Rotor side converter to enhance the Low voltage ride through capability of DFIGs.

\section{PROPOSED SYSTEM :}

\section{A. Block Diagram of DFIG System}

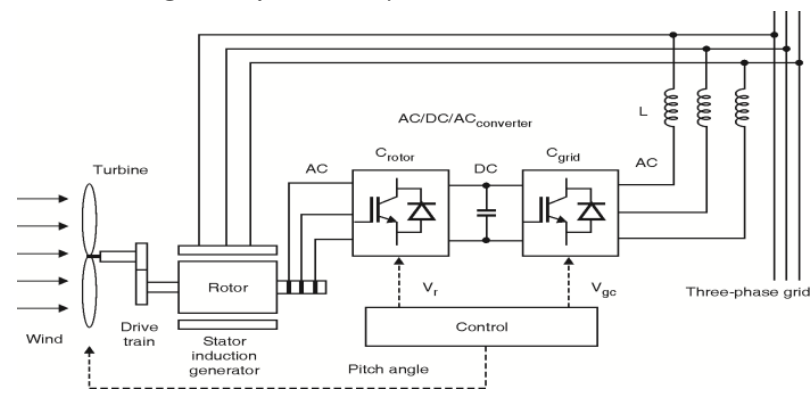

Fig .1 Basic configuration of DGIF system

Fig. 1 shows the basic block diagram of the wind turbine system where DFIG is connected to the wind turbine through a gearbox. The stator of the DFIG is directly connected to the grid and rotor is also connected to the grid but via a AC DC AC converter. The converter on the rotor side is well known as rotor side converter and the line side converter is called as grid side converter. The power flow from the DFIG is controlled by injecting the appropriate voltage at different frequencies through the RSC to the rotor circuit in sub synchronous as well as super synchronous speed. Therefore, RSC and GSC consist of four-quadrant IGBT operation with PWM technique. These converters are connected to each other by a common dc-link capacitor. [5] [6].

\section{B. Feed forward current regulator}

RSC Current Controller scheme

To control the DFIG RSC and GSC the conventional vector control scheme is commonly used. The main advantage of this system is that it offers a good decoupled control of the active and reactive power [10].

The $\mathrm{d}-\mathrm{q}$ transformation is adopted for the modeling. Figure 2 and figure 3 shows the control block diagrams for 
the rotor side and grid side converters respectively. For the controlling the rotor side converter the $d$-axis is oriented with the stator flux vector, and to control the grid side converter the $d$-axis is oriented with the stator voltage space vector.

The active power or electromagnetic torque is related to the $q$-axis rotor current $i_{q r}^{e}$ and the reactive power is related to the $d$-axis rotor current $i_{d r}^{e}$. This control scheme is known as the feed-forward current regulator. The scheme is derived from a steady state stator voltage and flux condition.

Block Diagrams

The block diagram of the conventional vector control schemes for the RSC and the GSC are shown in Figs. 2 and 3 respectively.

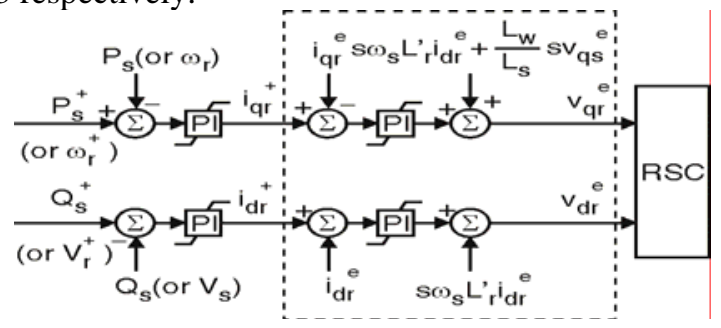

Fig 2 Vector control scheme for the RSC with traditional FFCR.

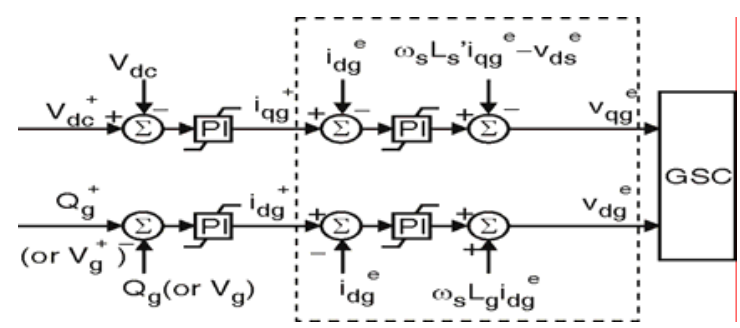

Fig 3 Vector control scheme for the GSC with traditional FFCR.

\section{Mathematical modeling}

The modeling of DFIG is done by considering the arbitrary reference frame. Equation 2.1 shows the $\mathrm{d}$ axis and $\mathrm{q}$ axis stator and rotor voltage respectively. The torque equation can be derived as mentioned in 2.2

$$
\begin{gathered}
v_{d s}=R_{s} i_{d s}+p \varphi_{d s}-\omega \varphi_{d s} \\
v_{q s}=R_{s} i_{q s}+p \lambda_{q s}+\omega \lambda_{q s} \\
v_{d r}=R_{r} i_{d r}+p \varphi_{d r}-\left(\omega-\omega_{r}\right) \varphi_{q r} \\
v_{q r}=R_{r} i_{q r}+p \varphi_{q r}+\left(\omega-\omega_{r}\right) \varphi_{d r} \\
\varphi=L_{s} i_{d s}+L_{m} i_{d r} \\
\varphi=L_{s} i_{q s}+L_{m} i_{q r} \\
\varphi=L_{m} i_{d s}+L_{r} i_{d r} \\
\varphi_{d r}=L_{m} i_{q s}+L_{r} i_{q r} \\
T_{e}=\frac{3}{2} \frac{P}{2} \frac{L_{m}}{L_{s}}\left(\varphi_{q s} i_{d r}-\varphi_{d s} i_{q r}\right)
\end{gathered}
$$

The electromagnetic torque Te depends only on $\mathrm{i}_{\mathrm{qr}}^{\mathrm{e}}$ instead of $\mathrm{i}_{\text {dr }}^{\mathrm{e}}$.

With some manipulations steady state model can be derived as,

$$
\begin{aligned}
& {\left[\begin{array}{l}
v_{d r}^{e} \\
v_{q r}^{e}
\end{array}\right]=\left[\begin{array}{cc}
R_{r}+L_{r}^{\prime} p & -s \omega L_{r}^{\prime} \\
s \omega L_{r}^{\prime} & R_{r}+L_{r}^{\prime} p
\end{array}\right]\left[\begin{array}{c}
i_{d r}^{e} \\
i_{q r}^{e}
\end{array}\right]+} \\
& s \frac{L_{m}}{L_{s}}\left[\begin{array}{c}
0 \\
v_{q s}^{e}
\end{array}\right]
\end{aligned}
$$

The feed-forward current regulator term in a Feed Forward Current Regulator are based on (2.3). In this scheme, the $\mathrm{d}$ axis and $\mathrm{q}$ axis rotor side current control loops are decoupled by injecting the cross-coupling current terms and the stator voltage coupling term. The PI regulator is used in d-axis and q-axis rotor current.

\section{Rotor Side Converter (RSC) scheme :}

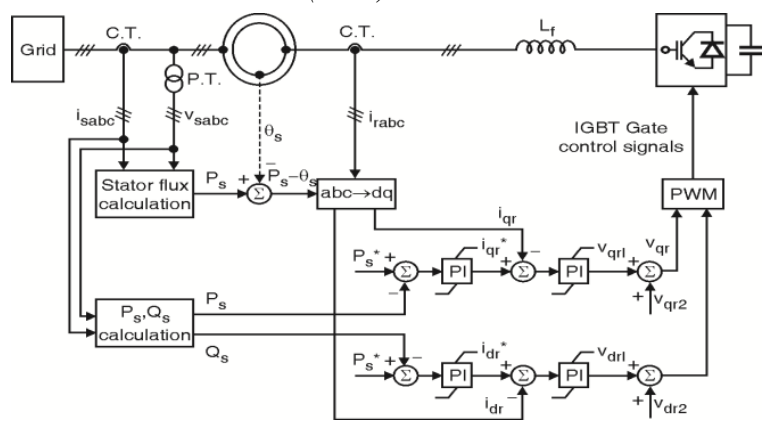

Fig 4 Rotor Side Convertor control scheme

The stator active and reactive power independent control is done by the RSC and these are represented by $P s$ and $Q s$, respectively. By controlling the reactive-power using the rotor side converter the stator voltage $V_{S}$ can be maintained within the desired limit especially when the DFIG is connected to a weak power system and having no reactive compensation.

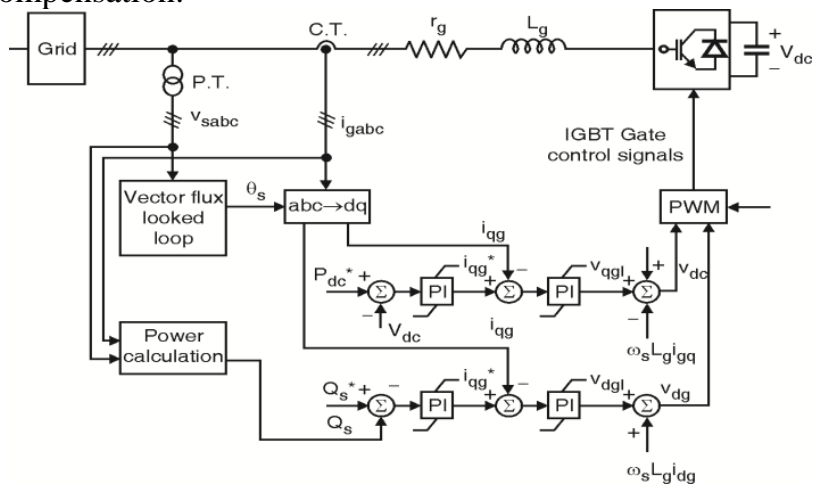

Fig 5 Overall control scheme of the Grid Side Convertor (GSC)

Overall Vector Control Scheme for RSC :

Fig. 4 shows the vector control scheme for the rotor side converter. The three phase currents $i_{\text {rabc }}$ are converted into the d-q currents namely $i_{d r}$ and $i_{q r}$ In the stator flux oriented reference frame. By controlling these currents independent control of the stator active power $P_{s}$ and reactive power $Q_{s}$. can be achieved. The reference values of $i_{d r}$ and $i_{q r}$ are achieved directly from values of $Q_{s}$ and $P_{s}$ respectively. The actual $d-q$ current signals $\left(i_{d r}\right.$ and $i_{q r}$ ) are then compared with these reference values $\left(i^{*}{ }_{d r}\right.$ and $\left.i^{*}{ }_{q r}\right)$ and then the error signal is generate. This signal is then passed through two PI 
controllers to form the voltage signals $v_{d r 1}$ and $v_{q r 1}$. The two voltage signals $\left(v_{d r 1}\right.$ and $\left.v_{q r 1}\right)$ are compensated by the corresponding cross-coupling terms $\left(v_{d r 2}\right.$ and $\left.v_{q r 2}\right)$ to form the $d-q$ voltage signals $v_{d r}$ and $v_{q r}$. This output is then used for the PWM technique to generate the gate control signals of rotor side IGBT convertor.

\section{E. Grid Side Converter (GSC) control scheme}

The grid side converter is primarily used to maintain the dc-link voltage to a constant value regardless of the magnitude and direction of the rotor power. The grid side converter can be set to control the reactive power exchange between the DFIG and the grid when the rotor side converter is blocked,.

\section{SIMULATION RESULTS \& ANALYSIS}

As per the problem discussed in the above sections, the model shown in the figure is developed to analyze the LVRT capability of the DFIG system using feed forward current regulator for the rotor side converter. Various conditions are set and the model is simulated to obtain the various results. Some conditions with their results are discussed in the following section. Balanced voltage sag of $0.9 \mathrm{PU}, 0.7 \mathrm{PU}$, $0.5 \mathrm{PU}, 0.3 \mathrm{PU}$ on the grid is set and the various results are captured. Out of which three voltage sag conditions are presented here (viz. 0.7 PU, 0.5PU and 0.3 PU). The duration of the sag is from 10 to 10.2 seconds. The main components to observe from the results are Stator current, rotor current, speed, and active and reactive power contributed by the DFIG along with the settling time of the DFIG after clearance of the fault. In case of voltage sag of $0.9 \mathrm{PU}, 0.7 \mathrm{PU}$ the rise in the stator current and rotor current is for very small duration and is within the safe limit. Also this current dies out very fast and settles to its normal value quickly, oscillations in the torque and rotor speed respectively and the values are also observed to be within the limit, the cases demands more attention are mentioned here for the sag of $0.5 \mathrm{PU}, 0.3 \mathrm{PU}$.

Case 1 :Voltage Sag 0.5 PU

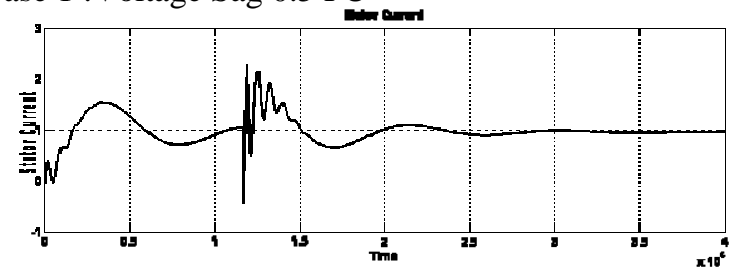

Fig. 6 Stator current

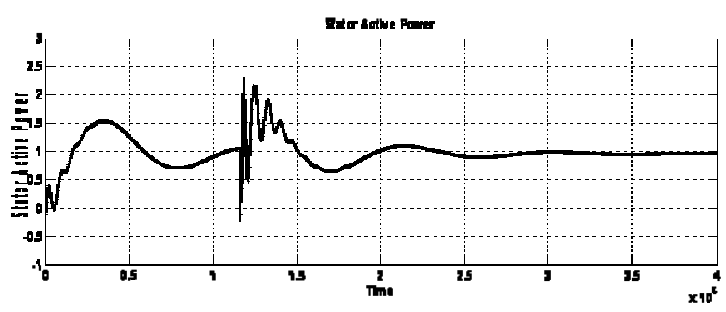

Fig. 7 Active Power

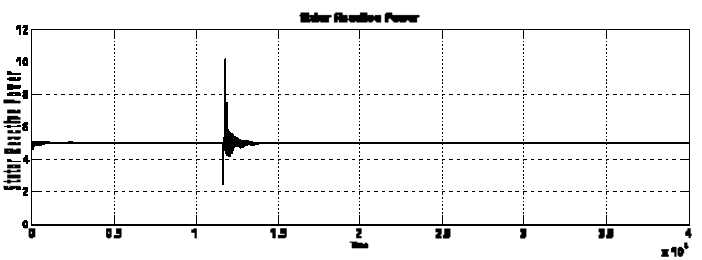

Fig. 8 Reactive Power

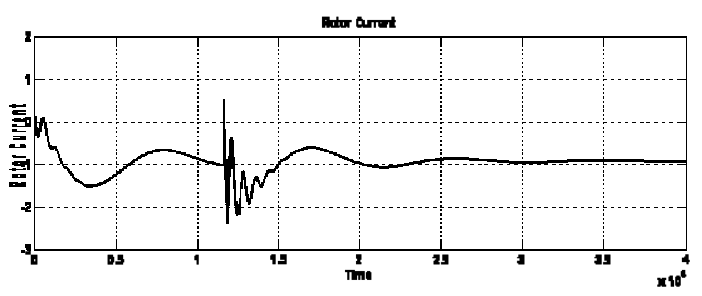

Fig. 9 Rotor current

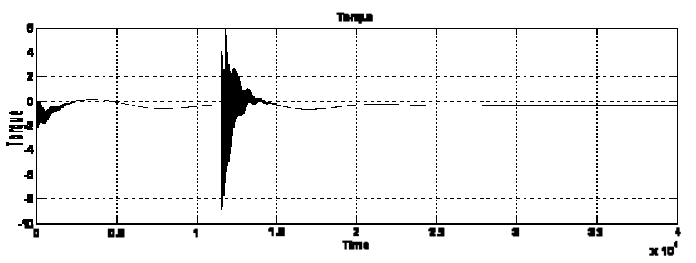

Fig. 10 Torque

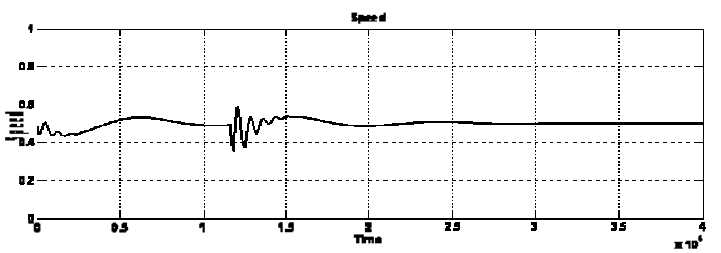

Fig. 11 Speed

Fig.3.1 DFIG performance at 0.5 PU voltage sag

Stator current corresponding to grid/stator voltage having $0.5 \mathrm{PU}$ sag is shown in figure 6 where the rise in the stator current is about 2.1 PU similarly figure 9 shows the rotor current. The rise in the stator current and rotor current is for small duration and is just reach to the unsafe limit. Since these currents dies out very fast and settles to its normal value quickly no immediate harm to the system. Fig. 10 and Fig. 11 shows the oscillations in the torque and rotor speed respectively and the values of torque has rise considerably which may oscillate the system at greater amplitude nad may damge the rotor and turbine system. Active and reactive power contributed by the DFIG during this condition is shown in figure Fig. 7 and Fig. 8 respectively.

Case 2 : Voltage Sag 0.3 PU

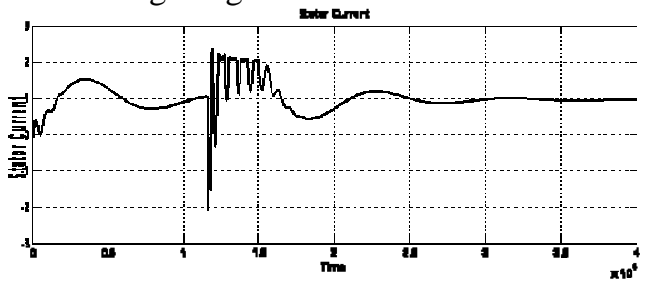

Fig. 12 Stator current 


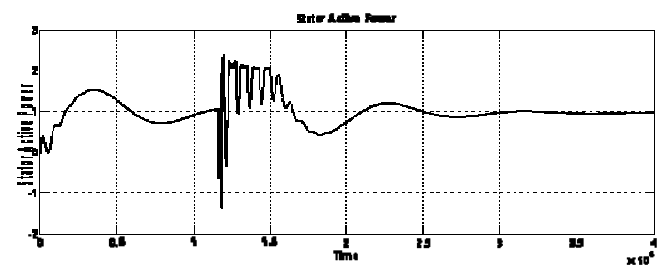

Fig. 13 Active Power

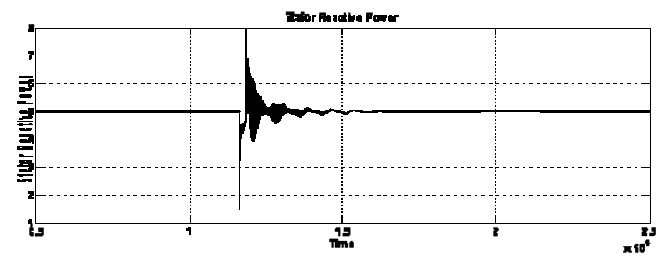

Fig. 14 Reactive Power

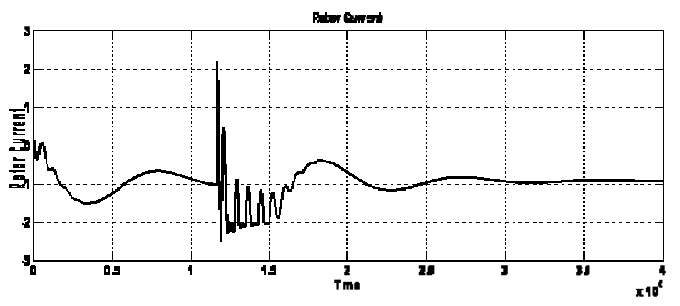

Fig. 15 Rotor current

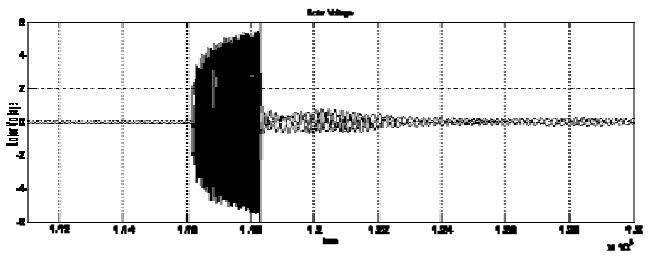

Fig. 16 Rotor Voltage

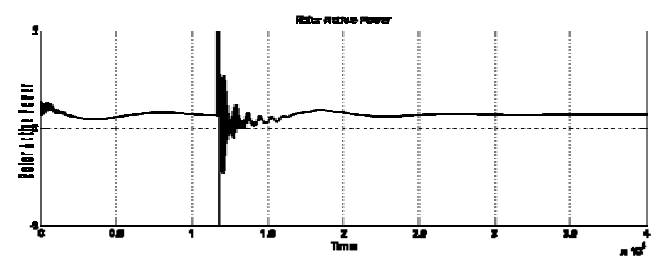

Fig. 17 Rotor active power

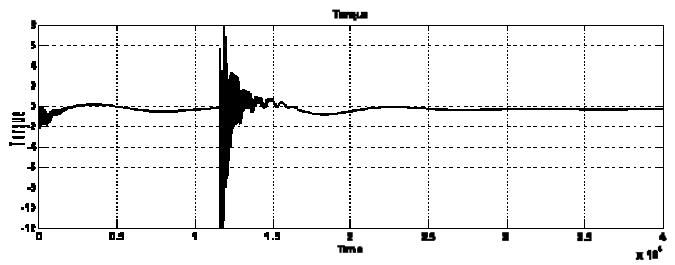

Fig. 18 Torque

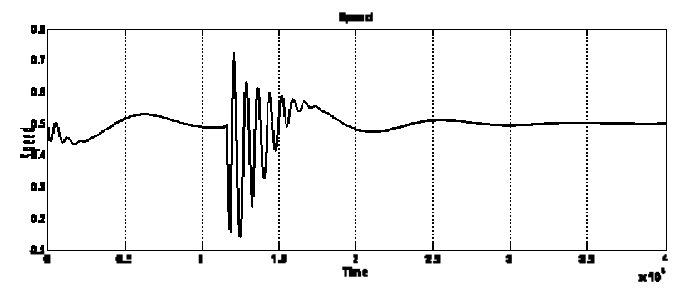

Fig. 19 Speed

Fig. DFIG performance at $0.3 \mathrm{PU}$ voltage sag

All the parameters of the DFIG has rise to unsafe magnitude. Stator current corresponding to grid/stator voltage having $0.3 \mathrm{PU}$ sag is shown in figure 12 where the rise in the stator current is about $2.3 \mathrm{PU}$ and oscillates between - ve and +ve values. Similarly figure $15 \& 16$ shows the rotor current whose magnitude has raised to $2.5 \mathrm{PU}$ and rotor voltage whose magnitude also raised to $5.2 \mathrm{PU}$. The rise in the stator current and rotor current is for longer duration and RSC and GSC need to be disconnected from the system to protect against such transient currents. Also the torque fig. 18 and the speed fig. 19 fluctuations are tremendously large and thus it may damage the mechanical system. The active and reactive powers are also reached to unsafe values.

\section{CONCLUSION}

When the wind turbines are equipped with the DFIGs then it is difficult to satisfy the low voltage ride through capability. Therefore uninterrupted power supply is difficult especially in voltage sag condition. An attempt is made to design the feed forward current regulator for the rotor side converter to limit the transients occurring in the rotor side power electronics. From the results it is observed that the LVRT of DFIG is considerably improved than the normal regulator and it may avoid the abrupt interruption of the DFIG under grid fault condition. It also minimizes the operation of crowbar circuit during the voltage sag condition and gives an uninterrupted reactive power support to the grid. It helps doubly fed induction generators to remain in operation even during severe grid faults.

\section{REFERENCES}

[1] W. Qiao and R. G. Harley, "Grid connection requirements and solutions for DFIG wind turbines," in Proc. IEEE Energy 2030 Conf., Atlanta, GA, Nov. 17-18, 2008, pp. 1-8.

[2] Federal Energy Regulatory Commission. (2005, Jun. 2). Regulatory Order No. 661: Interconnection for Wind Energy [Online].http://www.ferc.gov/industries/electric/indus-act/gi/wind.

[3] J. Lopez, P. Sanchis, X. Roboam, and L. Marroyo, "Dynamic behavior of the DFIG during three-phase voltage dips," IEEE Trans. Energy Convers., vol. 22, no. 3, pp. 709-717, Sep. 2005.

[4] J. Morren and S. W. H. de Hann, "Ride through of wind turbines with doubly-fed induction generator during a voltage dip," IEEE Trans. Energy Convers., vol. 20, no. 2, pp. 435-441, Jun. 2005.

[5] I. Erlich, H. Wrede, and C. Feltes, "Dynamic behavior of DFIG-based wind turbines during grid faults," in Proc. Power Convers. Conf. (PCC 2007), Nagoya, Japan, Apr. 2-5, pp. 1195-1200.

[6] C. Abbey and G. Joos, "Supercapacitor energy storage for wind energy applications,” IEEE Trans. Ind. Appl., vol. 43, no. 3, pp. 769776, May/Jun. 2005. 
[7] W. Qiao, W.Zhou, J. M. Aller, and R. G. Harley, "Wind speed estimation based sensorless output maximization control for a wind turbine driving a DFIG,” IEEE Trans. Power Electron., vol. 23, no. 3, pp. 1156-1169, May 2008.

[8] R. Lorenz andD. Lawson, "Performance of feed forward current regulators for field-oriented induction machine controllers," IEEE Trans. Ind. Appl., vol. IA-23, no. 4, pp. 597-602, Jul./Aug. 1985.
[9] E. Muljadi, C. P. Butterfield, B. Parsons, and A. Ellis, "Effect of variable speed wind turbine generator on stability of a weak grid,” IEEE Trans. Energy Convers., vol. 22, no. 1, pp. 29-36, Mar. 2005.

[10] S. M. Muyeen, R. Takahaski, M. H. Ali, T. Murata, and J. Tamura, "Transient stability augmentation of power system including wind farms by using ECS,” IEEE Trans. Power Syst., vol. 23, no. 3, pp. 1179-1187, Aug. 2008. 